\title{
Breaking Our Bonds and Reaffirming Our Connections
}

\section{Author(s): Maxine Hairston}

Source: College Composition and Communication, Vol. 36, No. 3 (Oct., 1985), pp. 272-282

Published by: National Council of Teachers of English

Stable URL: http://www.jstor.org/stable/357971

Accessed: 10-08-2016 16:00 UTC

Your use of the JSTOR archive indicates your acceptance of the Terms \& Conditions of Use, available at

http://about.jstor.org/terms

JSTOR is a not-for-profit service that helps scholars, researchers, and students discover, use, and build upon a wide range of content in a trusted digital archive. We use information technology and tools to increase productivity and facilitate new forms of scholarship. For more information about JSTOR, please contact support@jstor.org.

National Council of Teachers of English is collaborating with JSTOR to digitize, preserve and extend access to College Composition and Communication 


\title{
Breaking Our Bonds and Reaffirming Our Connections
}

\author{
Maxine Hairston
}

I'm very honored to be here today. Presiding over this meeting as your chair is a moving occasion for me because CCCC is an organization that has changed my life and shaped my career. I date that career from the first CCCC meeting I attended in New Orleans twelve years ago. At the time, although I was the director of freshman English at the University of Texas, I didn't consider myself a professional writing teacher. Rather I saw myself as an assistant professor trained in literature who had asked to run the writing program and got it because no one else in the department wanted it. At the New Orleans meeting, however, I discovered that other people were also interested in teaching writing, that it was actually a discipline that had journals and a body of scholarship, and that it offered the possibility of an exciting career. That career has been more rewarding than I could have imagined twelve years ago.

When I look back on those twelve years in our profession, I find them amazing. We have achieved a kind of national recognition that didn't seem possible in 1973 . We now have at least a dozen nationally recognized graduate programs granting degrees in rhetoric and compositon, and more are being established every year. We are teaching courses in rhetorical history and theory that didn't exist ten years ago. Many departments are also adding positions in rhetoric and composition in their departments. In fact, the job market for rhetoric and composition faculty, both senior and junior, is excellent. We have dozens of regional writing projects for school teachers that have grown out of James Gray's Bay Area Writing Project, and writing across the curriculum has become a by-word in colleges and universities all over the country. We have at least half a dozen new journals focusing on writing and the teaching of writing, and in the past few years several scholars in the field have been awarded major grants for improving the teaching of writing. Membership in CCCC and attendance at conventions are at an all-time high, and the new peo-

Maxine Hairston, Professor of English at the University of Texas at Austin, is this year's Chair of CCCC. This essay is a slightly revised version of her Chair's address to the annual convention in Minneapolis. Professor Hairston has contributed frequently to College English and to $C C C$, and she is the author of several textbooks, including texts for advanced courses in writing. 
ple coming into the profession are energetic, enthusiastic, and bright scholars who are generating theories and doing research that is accelerating change in the discipline. We have also caught the attention of the general public, and in many ways I think the climate for doing our job is better than it has ever been.

But most encouraging to me are the major changes I have seen in the teaching of writing. The teaching assistants in my graduate classes, the apprentice teachers whom I supervise, the teachers I talk and work with at seminars and writing workshops around the country are so much better than I was when I started that there is no comparison. They like what they're doing, they are confident, enthusiastic, and committed, and they are eager to learn. I am always delighted at how many fine writing teachers I find in places like Parsons, Kansas, or McAllen, Texas, or Montgomery County, Maryland.

So I think that as a profession we have come a long way in a short time, and from a broad perspective one can say that we are doing remarkably well. But that may seem like a rose-colored view when one looks at the situation of writing teachers from the narrower perspective one gets within individual institutions. There we often find ourselves confronting the literature faculty who dominate so many departments, and we feel that we are fighting losing battles: battles to get hard money to staff the writing center, battles to establish programs for training writing teachers, or battles against staffing composition courses with underpaid, low-status, part-timers. Fighting that literature faction often makes you feel like you have invaded China. You can mount an allout assault and think you're making an impression, but when the smoke clears, nothing has changed. The mandarins are untouched.

I could cite a dozen similar examples that contradict my happy view and illustrate that we in the composition field still have major problems. And I agree. We do. But our experience is much like that of the women's movement. One can look at how far we have come and rejoice at our progress, or one can look at the barriers that still exist and become discouraged. I believe, however - and once more the situation is analogous to that of many womenthat a major reason we get discouraged is that our worst problems originate close to home: in our own departments and within the discipline of English studies itself. And we are having trouble solving those problems precisely because they are so immediate and daily, and because we have complex psychological bonds to the people who so frequently are our adversaries in our efforts to make the writing programs in our departments as good as they should be and can be.

I think the time has come to break those bonds-not necessarily physically, although in some cases that may be a good idea-but emotionally and intellectually. I think that as rhetoricians and writing teachers we will come of age and become autonomous professionals with a discipline of our own only if we can make a psychological break with the literary critics who today dominate the profession of English studies. Until we move out from behind their shad- 
ows and no longer accept their definition of what our profession should be, we are not going to have full confidence in our own mission and our own professionalism. I agree that logically we should not have to choose. English studies should not be split between a commitment to teaching literature and a commitment to teaching writing. After all, what could be more central to English studies than teaching people to write? But logic has long since ceased to be a consideration in this dispute. I think that for the literary establishment, the issue is power; they do not want to relinquish their control of all of English. For us, I think the issue is survival. We must cut our psychological dependence in order to mature.

In some ways, of course, we have made the separation. We are earning our living teaching writing, and we do have our own professional meetings and journals and a developing body of scholarship. We have a sense of purpose and a camaraderie that energizes the profession. But $I$ also see us stunted in our growth because we are not able to free ourselves from needing the approval of the literature people. We've left home in many ways, but we haven't cut the cord. We still crave love.

For example:

We keep trying to find ways to join contemporary literary theory with composition theory. Such a goal makes sense in many ways', but people who are trying to achieve it seem to be on a one-way street - they are eager to find ways by which we can use literary theory in the teaching of writing, but I hear no one talking about using what we know about writing processes to help us teach literature. Nor do I see any prospect of setting up a dialogue with the literary critics on this matter because they don't know writing theory and, as far as I know, are making no attempt to learn.

Moreover, I suspect that in many of the articles which try to link literary theory and composition theory, the authors, perhaps unconsciously, have purposes that go beyond developing new ideas about the teaching of writing. They also want to show their former mentors that even though they are now composition teachers, their hearts are still pure. They do that by demonstrating that they have read the scholarship of deconstructionism and semiotics and take it seriously. By bringing in the magic names-Cullers, Fish, Hartman, and Derrida - they signal that they have not abandoned the faith.

We have also shown our insecurity by the effusive welcomes we have given several eminent literary scholars who, distressed about the quality of their students' writing, have now and then joined forces with us to contribute their ideas about teaching writing. Their efforts were honest but had little major impact; after all, their primary interests lay elsewhere. Still, without waiting for them to prove themselves by conference papers or committee work, we eagerly asked them to be keynote speakers and panelists, telling ourselves that if we could get them on our side, others in the literary establishment would take us more seriously and pay attention to our new discipline. The establishment, however, seems to have paid little attention. We are not being published in their journals, and they are not seeking to be published in ours. 
Many of us have also revealed our nervousness about our own discipline by encouraging our graduate students to combine rhetoric and composition with literary criticism in graduate programs and their dissertations, assuming that their degrees would be more marketable in traditional English departments. That's an untested assumption, and I think it can be a damaging one. Its effect is to suggest that we fear that our own discipline may not be scholarly and substantive enough for a graduate student to specialize in it exclusively and write a dissertation in it.

Finally, in the recurring fracases with the literature people-I think of them as the Mandarin Wars-we seem always to be the ones who propose reconciliation. We are the ones who propose panels at MLA on bridging the gap between composition and literature and who edit books on the reading-writing connection. We are the ones who ask that composition people be appointed to the editorial board of $P M L A$. We are the ones who say, "But we need each other. Look how many students we teach in composition, how much money we generate for the department. If we can just focus on our common goals and talk to each other, we can work things out." We act as if we are the ones who have the most to lose in this clash of cultures we're engaged in. For that is what the Mandarin wars are all about-they are battles against a patriarchal culture whose values we absorbed early.

But before we compromise too much, I think we need to look at that culture as it is today and decide how strongly we still believe in the values with which we were raised. And I stress "today" because I think that in many ways the culture of English studies has changed significantly in the last ten years. In my department, at least, and in many of those I hear about from my colleagues, the commitment to literature itself and to teaching students to enjoy literature that made most of us join this profession seems to have faded and to have been replaced by a commitment to criticism for its own sake. Somehow the experience of reading literature for pleasure has gotten lost. Now one can find graduate seminars in which students spend thirty minutes discussing a major novel and four hours analyzing the criticism on the book.

But in another important way English studies basn't changed; in traditional departments the system still dictates that the hardest work of the department, teaching freshman writing, remains at the bottom of the social and political scale. Typically that work is done by underpaid graduate students who are given to understand that once they have served their apprenticeships and completed their Ph.D.s, they will be largely exempt from such chores. As their number has declined, an even lower class has been hired to take up the slack: anonymous, underpaid, and conveniently invisible adjunct faculty. In many schools such faculty teach the bulk of the writing courses. Tenured professors continue to do the "real" work of the department, which is understood to be teaching literature, preferably English, preferably poetry, preferably difficult. And most of the professors who specialize in these areas have not taught freshman composition in so long that they claim, with justification, that they are no longer qualified to do it. 
I see no evidence that this value system is going to change in most universities. I think it reflects an elitist mindset that prefers that which is accessible only to the few and that despises the useful or the popular. The attitude is the same one that made Chinese mandarins grow long fingernails and decree that their women must bind their feet. (Notice that the women also thought the bound feet were beautiful.) And in the minds of most of today's criticscholars, their handicaps, their inability to do useful work or communicate with non-specialists, have become advantages because they separate them from the masses. And we have to face the truth that our mandarins think we are ugly because we have short fingernails and big feet. Nothing is going to change that.

The fact that as writing teachers we are useful to them-indeed, that they probably couldn't survive without us-only makes them more contemptuous. They see us in a service role; we do the work they don't want to do. and when we accept their definition of writing courses as service courses, we ourselves denigrate what we do and buy into their value system. We take on the martyr role of faithful but underpaid and undervalued caretakers who make it possible for the elite to survive. Too often, like so many caretakers, we rationalize and romanticize our role.

Another enduring feature of traditional English departments-and, in fact, of the academic world in general-is that the faculty tends to take a Platonic view of the world, detached and slightly contemptuous of daily work and everyday concerns. Typically, academics are introverted, contemplative sorts who prefer, as Bertrand Russell says, to work in "that happy realm of exactness where pure thought can disport itself in freedom." In English studies they can come closest to finding those happy realms by focusing on writing from the past and by resolutely claiming that any practical enterprise, such as teaching technical or expository writing, is not a legitimate concern of a department of literature.

It is also clear that the scholar-critics in most departments don't believe in the teaching of writing as a discipline. They are uninterested in what we have learned about teaching writing and believe we have nothing to teach them. Some of them openly dismiss our research and scholarship as trivial. Anyone who has taught writing-across-the-curriculum workshops will tell you that the English faculty are the least likely to attend and the most difficult to work with when they do attend.

Now I know I am generalizing and that not everyone whose primary interst is teaching and writing about literature fits the stereotype I have drawn. Almost every department has many thoughtful and open-minded scholars who enjoy teaching both literature and writing and do both reasonably well. They tend not to be the faculty who are politically active, however; usually they just want to be left alone to pursue their scholarship. The politically active literary critics, on the other hand, are "full of passionate intensity" and have an effect that belies their numbers. If we are going to hold our own against them, the 
question we must face, the question that will not go away, is "How can we rally our forces against this intimate enemy?"

Whatever we do is going to be difficult and painful precisely because the enemy is intimate, a member of the family, and because we are going to have to take the risks that accompany assertion and separation. But I think we must begin. First, I think we need to realize that at the present time we are wasting our time trying to establish a dialogue. In addressing the mandarins, we are not in a rhetorical situation. You'll remember Lloyd Bitzer says that in order to have a rhetorical situation there has to be an exigence that can be modified by discourse, and there has to be an audience of persons who are capable of being influenced by that discourse. ${ }^{1}$ Chaim Perelman also reminds us that the specific requisite for argumentation is this: "the speaker can choose as his points of departure only those theses accepted by those he addresses." 2 In most of our departments right now, I don't think we have either of those conditions.

We perceive an exigence-we see that much of the writing in our departments is being badly taught by untrained and overworked people or by disaffected literature specialists who see their students as hopeless illiterates. We see our students being short-changed, and we want to change that. We alsc want the literature faculty to recognize the value of what we are doing and to commit themselves to supporting writing programs and writing faculty. But those are our needs, not theirs, and they're not paying any attention. Nor will they until we force them to do so.

Nor do I think that in most institutions we are dealing with an audience who is capable of being influenced by our discourse or who shares our basic premises about teaching writing. From my experience in doing faculty workshops, from talks I have heard at regional and national conferences, and from discussions I have had with colleagues across the country, I have to conclude that most literature faculty do not want to hear what we have to say; they already know a priori that the best way to teach writing is to have students read good literature and write about it. Their cry is that otherwise the courses have no content, and they refuse to concede that the content of a writing course is language and how it works. They have no interest in the new paradigm that stresses working with students during the writing process and that draws on the insights of cognitive psychology about how people learn. They prefer to teach writing by talking about literature in a teacher-centered classroom.

In many institutions, it's clear that a majority of the English department faculty do not share our conviction that English departments have an obligation to teach people to write. If students do not already know how to write when they get to college, they hold, that is somebody else's fault and we shouldn't have to deal with it. It's much easier to invoke the magic phrase "rigorous standards" and proclaim that since students should have learned to write in high school, freshman English is a remedial course that we shouldn't have to teach. 
So this is the first lesson we have to learn: THEY'RE NOT LISTENING. We are wasting our energy pummeling at them and trying to get them to acknowledge our claims or our merit. As long as we do that, we are playing their game. And it's a game we can't win because they made the rules and they are the referees.

My second suggestion is that we quit wasting our time being angry. Getting angry can be useful at times, particularly if it helps one get rid of illusions and decide to take action, but staying angry consumes too much energy. When we let people keep us in an uproar, we give them too much importance and risk assuming that they are more powerful than they really are. The mandarins aren't really as monolithic and secure as we give them credit for being. Their world has changed a great deal in the past decade: fewer students are enrolling in their courses, their graduate students can't find jobs, and most of the professors themselves are no longer mobile. The openings in literature just aren't there. It's not surprising that they feel threatened by our new success. I suspect, moreover, that many of them know that they're like dinosaurs standing around waiting for the weather to change, that things are never really going to be the same again. But instead of trying to shout them down, I think we will do better to spend our energy building our own reputations and enhancing our status outside of our departments instead of over-reacting to hostility at home.

Our third important task is the same one that women and minorities have faced in the last two decades: we must pay attention to what our inner selves tell us, find our own values and listen to our own voices-values and voices that are not against someone else, but for ourselves. We must no longer try to be "good" by trying to live up to someone else's visions for us by saying, "Tell me what you want me to be and I'll be it. I want to please you." If we do that, when we win, we lose.

Instead, we need to listen to our voices when they tell us what is true for us even when those messages conflict with the conventional wisdom in which we have been schooled. For instance, our voices may be telling us that teaching freshmen is more rewarding than teaching graduate students; that our students are not illiterates, but intelligent, competent young people who like to write; that writing courses are not service courses, but courses in the exercise of a primary intellectual activity; that we value writing textbooks as much as we value writing scholarly books because we value teaching as much as we do scholarship. Especially we should pay attention to our own feelings when they confirm a response that some of us used to be ashamed to admit: that we genuinely enjoy teaching the writing courses that other faculty profess to despise. We must listen to our different drummer and pay attention.

For we are different. As writing teachers we are engaged in a dynamic and loosely-structured activity that involves intensive interaction with people. It is an activity that is tied to living language, that shifting and ambiguous medium that won't stand still to be examined and is never pure, and it is an ac- 
tivity that focuses on teaching a process for which there are no fixed rules and no predictably precise outcomes. We are engaged in a messy business, and necessarily so. And it's one that is essentially Aristotelian-pragmatic, concrete, situational, and personal.

But once we have established who we are and what we do, we face the challenge of establishing our discipline on solid ground, both in the academic community and in the community beyond the university and college. To meet that challenge, we must take a number of steps.

First, as individuals we must be productive researchers and scholars who contribute to the growth of our discipline. We cannot rely simply on being good teachers even though that may be our first priority: in the league we want to play in, that's not enough. Unless we know our past and unless we can construct theoretical frameworks that inform our practice, we will not be taken seriously. Nor should we be; being a professional means more than having a knack for one's trade.

We also have to publish: in the league we're in, that's a given. But it's useful to remember that publication does more for professionals than bring recognition and advance the state of the art. It also helps us as individuals to build the self-esteem and confidence that is especially important for beginners in an enterprise, and it gives us the rewards and reinforcement from outside our institution that most of us do not get in our own departments. Moreover, the writers and doers in a profession quickly establish a camaraderie with each other and get the important satisfaction of feeling that they are participating in a vital activity.

As scholars and writers, we also have to set high standards for our research, our conferences, our publications, and for our own writing, and we have to do first-class work in all our diverse activities. It's important, however, for us to realize that ours is a humanistic discipline, and that we cannot yield to what Lewis Thomas calls "physics envy," the temptation to seek status by doing only empirical experiments that can be objectively normed and statistically validated. If we do that we will narrow our field of inquiry to investigations that are so limited that what we find out will be worthless to us as writing teachers.

Indeed, it is precisely because our work cannot be judged by scientific standards that we have to set exacting criteria for ourselves and do rational, thorough, and informed investigation. We have to learn to formulate good questions, to examine data-especially data that come to us in languagesensitively and meticulously, to control for bias, and to be careful not to claim too much for our findings. We must demand of each other the kind of quality scholarship that will make us proud of the work being done in our field and earn us the respect of scholars outside the field. In fact, one of our major challenges now is to develop guidelines to define and govern good research.

Second, we have to extend our connections to disciplines outside our fieldnot only to linguistics, philosophy, cognitive psychology, and speech commu- 
nication, but to less obviously connected fields such as biology, economics, and even the arts. Since rhetoric is a way of learning, every human intellectual enterprise involves writing and rhetoric, and we can learn from all disciplines and help others in all disciplines. And by establishing connections and credibility outside of English departments, we stand to improve our standing with the whole university community.

Finally, we need to reach beyond our immediate world and make connections with business, industry, technology, and the government. These institutions are running a giant educational operation, and we have an opportunity both to learn from them and to contribute to their enterprises. By working with them, we can take an active part in shaping today's information society.

If we can do all of this, we may get our literary colleagues' attention and their respect as they realize that we have gained credibility and influence outside of the department, and that we no longer look to them to validate our worth. Then they may begin to change their attitudes, decide that they need us after all, and that we should work together to resolve our differences. But that may not happen, too. Then what? Is separation the only answer?

Not necessarily, but at that point I think we should look at our options. Probably most composition and rhetoric faculty would prefer to keep their affiliation to English departments, and I think that that's a good solution if we can stay as equals. It is not a good solution if the patriarchal hierarchy of those departments continues to deny English departments' responsibility for teaching undergraduates to write, to demean our work, and to tilt the reward system in favor of literary criticism. We now have too many choices to accept those conditions.

As a group, one of our choices might be to work directly with a sympathetic chairman to get what we want for our writing programs; often department chairs are more practical than their faculty and want broad-based programs that serve undergraduate needs. Another option may be to enlist the help of a dean or provost who realizes how important the writing program is to the college or university. Composition faculty can also consolidate their position and expand their influence by working together to get national grants that will catch the attention of the upper administration. And in departments that have three or four rhetoric and composition faculty now and are hiring more, the answer may be "Be patient." As the new generation takes over, the power will shift.

Our most radical option, of course, would be to petition to split the composition and rhetoric program from the English department and form a department of rhetoric. If we do that, we could be helping to initiate what James Kinneavy has called the return of rhetoric from exile. ${ }^{3}$ Rhetorical studies held the center of humanistic studies until the seventeenth century, and were a major component in American departments of English until early in the twentieth century. Then the same kind of dispute between those who wanted to focus their efforts exclusively on the study of literature and those 
who wanted to include the study of oral rhetoric and the craft of writing caused those committed to rhetoric to leave and form departments of speech communication. Perhaps it's time that we repeated the exodus, this time taking freshman English with us. Perhaps we should even consider joining with speech communication and journalism to form a new and vital department of language and communication, and once more make humanism and rhetoric relevant in our modern society. This option would be the most disruptive and most difficult; to me, at the present time, it would also be the best.

If you as an individual writing teacher believe that your department is hopeless, and you think you can't wait for that utopian solution, it's not too difficult to find other, more immediate, options. One is to move to another college or university. Not all departments fit the discouraging picture I have described, and many are expanding their rhetoric programs or starting new ones. You might also consider talking to the deans of some of the professional schools at your university-law or engineering, for example-about starting a writing program that would meet the special needs of their students. You could become a technical writer; you could set up a research and consulting firm; you could try to break into corporate education or become the director of writing and publicity for a bank or a computer company. Anyone who is an energetic and skillful teacher, writer, and researcher has a wide range of options open. To be sure, they all involve taking risks, and many involve giving up some of the bonuses of academia - the flexible schedules, the month-long vacations, the contact with students. But they also have their own kind of challenges and satisfactions and their own rewards, both intellectual and financial.

For anyone, these are drastic solutions, not to be undertaken lightly. There are no guarantees and not many models to look to for guidance. But the cost in anger and frustration is also high if we do nothing, thinking that the climate is going to change if we wait long enough. If we want to cause change instead of wait for it, if we want the profession of teaching writing to become a recognized and respected intellectual discipline, we are going to have to believe in ourselves and in what we do strongly enough to be willing to take a chance and break with the power structure if necessary. We have to know that we can make it without them, for only if we are ready to leave are we going to be able to participate in the relationship as equals. When we can honestly say, "We no longer need your approval," their power over us will dissolve. But as long as we're afraid, we'll lose the struggle.

I hope that we will emerge from this dispute stronger because we have been willing to take a stand affirming that we are professional teachers of writing, and that we intend to put our primary energy into the teaching of writing and into research that informs the teaching of writing because we believe those concerns are central to English studies. By saying this we do not intend to diminish literature or the teaching of literature; we should always make that clear. But we can learn from the feminist psychologists that when we have the 
courage to assert ourselves, the bond of dependence can give way to a dynamic of interdependence. ${ }^{4}$ If that happens, perhaps we can once more engage in a mutually satisfying dialogue with a group for whose traditions we once felt an affinity. By freeing ourselves, we may finally establish that dialogue. and by leaving the house in which we grew up, we may finally create the strong connection between literature and composition that most of us feel is good and natural.

\section{Notes} $1-15$

1. Lloyd Bitzer, "The Rhetorical Situation," Philosopby and Rbetoric, 1 (Winter, 1968),

2. Chaim Perelman, The Realm of Rhetoric (Notre Dame, IN: University of Notre Dame Press, 1982), p. 21.

3. James Kinneavy, "Restoring the Humanities: The Return of Rhetoric from Exile," in The Rhetorical Tradition and Modern Writing, ed. James J. Murphy (New York: Modern Language Association, 1982), pp. 19-28. 149.

4. Carol Gilligan, In a Different Voice (Cambridge, MA: Harvard University Press, 1982), p.

\section{CCCC Writing Workshop-Proposals Invited}

The officers of the Conference on College Composition and Communication plan to submit a proposal for a CCCC Writing Workshop to the Program Chair of the 1986 National Council of Teachers of English Convention, to be held in San Antonio, Texas. Members are invited to develop proposals for full-day workshops for a general audience of college and high school teachers. The deadline for proposals is 15 November 1985.

For more information and a proposal form, send a stamped, self-addressed envelope to Erika Lindemann, CCCC Secretary, Department of English, University of North Carolina at Chapel Hill, Chapel Hill, NC 27514.

\section{The New Society for Language and Rhetoric}

The Department of English at the University of Illinois at Chicago announces the formation of the New Society for Language and Rhetoric. The purpose of the society - successor to the Great Lakes Area Rhetoric Association-is to advance teaching and research in the uses of language. The first meeting of the society will be held on Saturday 16 November 1985, on the campus of the University of Illinois at Chicago. Among those on the program for this all-day meeting are Marilyn S. Cooper, University of Southern California; Martin Nystrand, University of Wisconsin at Madison; Roger W. Shuy, Georgetown University; Joseph M. Williams, University of Chicago. Further information is available from Martin Steinmann, Jr., at the University of Illinois at Chicago. 